\title{
Exploring the Innovative Aspects of CV Distributed Ledgers Based on Blockchain
}

World Conference on Information Systems and Technologies

WorldCIST 2020: Trends and Innovations in Information Systems and Technologies pp 14-24 | Cite as

- F. O. Silva (1)

- Rui Humberto Pereira (1)

- Maria José Angélico Gonçalves (1) Email author (mjose@iscap.ipp.pt)

- Amélia Ferreira da Silva (1)

- Manuel Silva (1)

1. CEOS.P, Porto Accounting and Business School, Polytechnic of Porto, , Porto, Portugal

Conference paper

First Online: o8 June 2020

- 650 Downloads

Part of the Advances in Intelligent Systems and Computing book series (AISC, volume 1160)

\begin{abstract}
Blockchain is a distributed ledger technology aimed at decentralization and transparency. A blockchain record is immutable, which means that once created by an entity, no other can change what enables legitimacy checking. These are key features to ensure the accuracy of records with sensitive information such as the issuance of records of competencies and qualification certificates when issued by certified entities (education institutions, professional formation schools, companies, etc.). This paper aims to identify the most innovative aspects in CV records management systems based on a blockchain paradigm. In order to engage this objective, an assertive literature review of the CORDIS (The Community Research and Development Information Service (https://cordis.europa.eu/ (https://cordis.europa.eu/))) database was performed and discussed. The results are depicted and enable orientations to future work.
\end{abstract}

\section{Keywords}

Blockchain CV distributed databases Competencies and qualifications

Partners collaborative network Emergent technologies

This is a preview of subscription content, $\underline{\log } \underline{\text { in }}$ to check access. 


\section{References}

1. Armstrong, R., Hall, B.J., Doyle, J., Waters, E.: Cochrane update. "Scoping the scope" of a cochrane review. J. Public Health (Oxf.) 33(1), 147-150 (2011). https://doi.org/10.1093/pubmed/fdro15

(https://doi.org/10.1093/pubmed/fdro15)

CrossRef (https://doi.org/10.1093/pubmed/fdro15)

Google Scholar (http://scholar.google.com/scholar_lookup?

title=Cochrane\%2oupdate.\%20\%E2\%80\%9CScoping\%20the\%20scope\%E2\%8 0\%9D\%20of\%20a\%20cochrane\%20review\&author=R.\%20Armstrong\&author $=$ BJ.\%20Hall\&author $=$ J.\%20Doyle\&author $=$ E.\%20Waters\&journal=J.\%20Pub lic\%20Health\%20\%280xf.\%29\&volume=33\&issue $=1$ \&pages $=147-$

150\&publication_year $=2011 \&$ doi=10.1093\%2Fpubmed\%2Ffdro15)

2. Swan, M.: Blockchain: Blueprint for a New Economy, 1st edn. O’Reilly Media, Sebastopol (2015)

Google Scholar (http://scholar.google.com/scholar_lookup?

title=Blockchain\%3A\%2oBlueprint\%20for\%20a\%20New\%2oEconomy\&author $=\mathrm{M} . \% 20$ Swan\&publication_year=2015)

3. PRISMA. http://prisma-statement.org/ (http://prisma-statement.org/). Accessed 22 Oct 2019

4. Dang, Q.A.: The Bologna process goes East? from "Third Countries" to prioritizing inter-regional cooperation between the ASEAN and EU. In: Curaj, A., Matei, L., Pricopie, R., Salmi, J., Scott, P. (eds.) The European Higher Education Area: Between Critical Reflections and Future Policies, pp. 763-783. Springer, Cham (2015)

CrossRef (https://doi.org/10.1007/978-3-319-20877-0_47)

Google Scholar (http://scholar.google.com/scholar_lookup? title=The\%20Bologna\%2oprocess\%20goes\%20East\%3F\%20from\%20\%E2\%8o \%9CThird\%20Countries\%E2\%80\%9D\%20to\%2oprioritizing\%2ointerregional\%20cooperation\%2obetween\%20the\%20ASEAN\%20and\%2oEU\&auth or $=$ QA.\%20Dang\&pages $=763-783 \&$ publication $\_$year $=2015$ )

5. Blockchains in the new era of participatory media experience-BLOOMEN Project-H2020-CORDIS-European Commission. https://cordis.europa.eu/project/rcn/211092/factsheet/en (https://cordis.europa.eu/project/rcn/211092/factsheet/en). Accessed 17 Oct 2019

6. 'Decentralised Qualifications' Verification and Management for Learner Empowerment, Education Reengineering and Public Sector TransformationQualiChain Project-H2020-CORDIS-European Commission. https://cordis.europa.eu/project/rcn/218758/factsheet/en (https://cordis.europa.eu/project/rcn/218758/factsheet/en). Accessed 17 Nov 2019

7. Knowledge Publishing, Acquisition and Representation CORDIS-European Commission. https://cordis.europa.eu/project/rcn/195031/results/en (https://cordis.europa.eu/project/rcn/195031/results/en). Accessed 17 Oct 2019

8. The trusted solution for issuing certified documents to the blockchain, checkable in just a click CORDIS-European Commission.

https://cordis.europa.eu/project/rcn/220476/factsheet/en 
(https://cordis.europa.eu/project/rcn/220476/factsheet/en). Accessed 17 Oct 2019

9. An online digital logbook to protect and prove authorship, and to share scientific results-ResearchProof Project-H2020-CORDIS-European Commission. https://cordis.europa.eu/project/rcn/211312/factsheet/en (https://cordis.europa.eu/project/rcn/211312/factsheet/en). Accessed 17 Oct 2019

10. Nakamoto, S.: Bitcoin: A peer-to-peer electronic cash system (2008). https://bitcoin.org/bitcoin.pdf (https://bitcoin.org/bitcoin.pdf)

11. Fujimura, S., Watanabe, H., Nakadaira, A., Yamada, T., Akutsu, A., Kishigami, J.J.: BRIGHT: a concept for a decentralized rights management system based on blockchain. In: 2015 IEEE 5th International Conference on Consumer Electronics - Berlin (ICCE-Berlin), pp. 345-346 (2015).

https://doi.org/10.1109/icce-berlin.2015.7391275

(https://doi.org/10.1109/icce-berlin.2015.7391275)

12. Palaiokrassas, G., Litke, A., Fragkos, G., Papaefthymiou, V., Varvarigou, T.:

Deploying blockchains for a new paradigm of media experience. In: Economics of Grids, Clouds, Systems and Services. Springer (2019)

Google Scholar (https://scholar.google.com/scholar?

q=Palaiokrassas\%2C\%20G.\%2C\%2OLitke\%2C\%20A.\%2C\%2oFragkos\%2C\%20

G.\%2C\%2oPapaefthymiou\%2C\%20V.\%2C\%20Varvarigou\%2C\%20T.\%3A\%20D eploying\%2oblockchains\%2ofor\%20a\%20new\%2oparadigm\%20of\%20media\% 20experience.\%20In\%3A\%20Economics\%20of\%20Grids\%2C\%20Clouds\%2C\% 20Systems\%20and\%20Services.\%20Springer\%20\%282019\%29)

13. Bloomen Project. Bloomen. http://bloomen.io/ (http://bloomen.io/). Accessed 17 Oct 2019

14. Garcia, A., Lopez, F., Conlon, M.: Thinking of a Blockchain for VIVO, 31 July 2017. https://doi.org/10.6084/m9.figshare.5259919.v1 (https://doi.org/10.6084/m9.figshare.5259919.v1)

15. Regulation (EU) No. 910/2014 of the European Parliament and of the Council of 23 July 2014 on electronic identification and trust services for electronic transactions in the internal market and repealing Directive 1999/93/EC, vol. 257 (2014)

Google Scholar (https://scholar.google.com/scholar?

q=Regulation\%20\%28EU\%29\%20No.\%20910\%2F2014\%20of\%20the\%20Euro pean\%20Parliament\%20and\%20of\%20the\%20Council\%20of\%2023\%20July\% 202014\%20on\%2oelectronic\%2oidentification\%20and\%2otrust\%20services\% 2ofor\%20electronic\%2otransactions\%20in\%20the\%2ointernal\%2omarket\%20 and\%2orepealing\%20Directive\%201999\%2F93\%2FEC\%2C\%2Ovol.\%20257\%2 0\%282014\%29)

16. KMI, D.D.: Qualichain. Qualichain. https://events.kmi.open.ac.uk/tlom (https://events.kmi.open.ac.uk/tlom). Accessed 17 Nov 2019

17. ISRL: ResearchProof. https://www.researchproof.com/ (https://www.researchproof.com/). Accessed 11 Nov 2019

18. Wood, G.: Ethereum: a secure decentralised generalised transaction ledger.

Ethereum Project Yellow Paper (2014)

Google Scholar (https://scholar.google.com/scholar? q=Wood\%2C\%20G.\%3A\%20Ethereum\%3A\%20a\%20secure\%2odecentralised \%2ogeneralised\%20transaction\%2oledger.\%20Ethereum\%2oProject\%20Yello w\%20Paper\%20\%282014\%29) 
19. Pokrovskaia, N.N., Spivak, V.A., Snisarenko, S.O.: Developing global qualification-competencies ledger on blockchain platform. In: 2018 XVII

Russian Scientific and Practical Conference on Planning and Teaching Engineering Staff for the Industrial and Economic Complex of the Region (PTES), pp. 209-212 (2018). https://doi.org/10.1109/ptes.2018.8604177 (https://doi.org/10.1109/ptes.2018.8604177)

20. Kalcheva, K., Yaffe, L., Petkov, P., Gountchev, T.: Jelurida (2017)

Google Scholar (https://scholar.google.com/scholar? q=Kalcheva\%2C\%20K.\%2C\%2OYaffe\%2C\%2OL.\%2C\%2OPetkov\%2C\%20P.\%2C \%2oGountchev\%2C\%20T.\%3A\%2OJelurida\%20\%282017\%29)

\section{Copyright information}

(C) The Editor(s) (if applicable) and The Author(s), under exclusive license to Springer Nature Switzerland AG 2020

\section{About this paper}

Cite this paper as:

Silva F.O., Pereira R.H., Gonçalves M.J.A., da Silva A.F., Silva M. (2020) Exploring the Innovative Aspects of CV Distributed Ledgers Based on Blockchain. In: Rocha Á., Adeli H., Reis L., Costanzo S., Orovic I., Moreira F. (eds) Trends and Innovations in Information Systems and Technologies. WorldCIST 2020. Advances in Intelligent Systems and Computing, vol 116o. Springer, Cham. https://doi.org/10.1007/978-3-030-456917_2

- First Online 08 June 2020

- DOI https://doi.org/10.1007/978-3-030-45691-7_2

- Publisher Name Springer, Cham

- Print ISBN 978-3-030-45690-0

- Online ISBN 978-3-030-45691-7

- eBook Packages Intelligent Technologies and Robotics Intelligent Technologies and Robotics $(\underline{\text { Ro }})$.

- Buy this book on publisher's site

- $\underline{\text { Reprints and Permissions }}$

\section{Personalised recommendations}

\section{SPRINGER NATURE}

(C) 2020 Springer Nature Switzerland AG. Part of $\underline{\text { Springer Nature. }}$

Not logged in Instituto Politécnico do Porto, member of B-on Consortium Portugal (3000182237) - B-on Consortium Portugal (3991329481) 193.136.56.65 